\title{
WSU and Microgravity Combustion Research at NASA Lewis Research Center
}

\author{
David N. Koert, David A. Nordling \\ Wichita State University \\ and \\ Daniel L. Dietrich \\ NASA Lewis Research Center
}

\begin{abstract}
"The training of a scientist is a long and expensive process. Studies clearly show that there are talented individuals in every part of the population, but with few exceptions, those without the means of buying higher education go without it."
\end{abstract}

Vannevar Bush (1945)

\section{INTRODUCTION}

The words of Vannevar Bush, father of the hypertext system, have an ominous ring in these days of uncertain funding for the sciences, diminishing financial-aid for students, waxing interest in science and even anti-science sentiment (Lederman, 1995). In an effort to promote interest in space-science among the potential scientists and engineers of the future, a multimedia presentation has been prepared as part of a NASA Educational Grant with Wichita State University (WSU). The presentation features video footage of a WSU engineering student floating weightlessly on a reduced gravity experimental flight as shown in Figure 1. The presentation uses colorful and attractive overheads describing an undergraduate research experience at NASA Lewis Research Center in the Space Experiments Division (this group develops experiments for the space shuttle and trains astronauts in their use). The presentation is supplemented with slide photographs and video tape of the work which was performed at NASA.

\section{BACKGROUND}

Since the early 1970's, microgravity science research has emerged as a new way to reveal the underlying physics and chemistry of combustion phenomena. The early work in microgravity combustion, and the majority of the work done thus far, has been conducted in ground-based facilities, i.e., the 2.2- and 5.18-Second Drop Towers at Lewis Research Center. However, these facilities, and the higher g-level parabolic trajectory jet

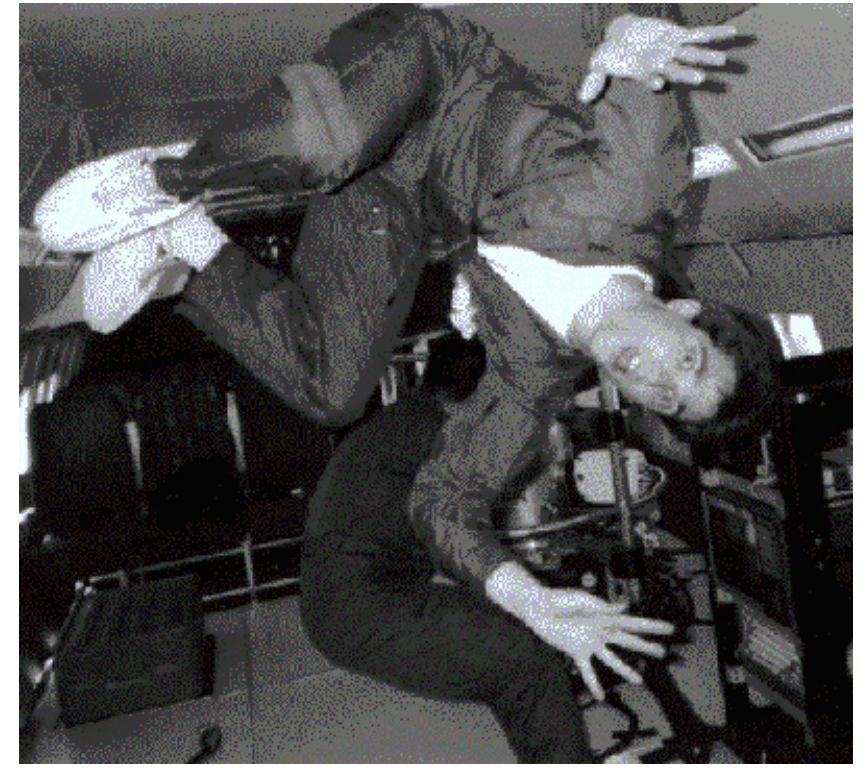

FIGURE 1. WSU engineering student David Nordling during a break between solid materials flammability experiments onboard NASA-Lewis' parabolic trajectory DC-9. 
aircraft, are limited by the time duration in which a microgravity environment is available. Space-based, long

duration, microgravity laboratories have only recently become available via space shuttle laboratories, and may be even more accessible in the future in Space Station Freedom. The capabilities of the reduced gravity test facilities, in terms of free-fall time and g-level, are summarized in Figure 2. With the advent of these unique, space based facilities, experiments are planned well into $21 \mathrm{st}$ century.

Ground-based, microgravity combustion science research has already established a solid base of experimental results in the areas of: solid materials flammability, premixed gas combustion, gas jet diffusion flames, droplet combustion, liquid pool fires, and particle cloud combustion. As a result of this preliminary work, many new phenomena have been discovered. For example in the area of premixed gas combustion, the destabilizing influence of buoyancy effects due to gravity have been demonstrated by simply taking photographs of premixed flat flame in zero-gravity and noting the lack of cellular structure. Similarly, in the area of particle cloud combustion which is a solid-gas analogue to the premixed gas flame, a so called "chattering flame" condition has been discovered also employing simple photographic methods.

It is interesting to note that advanced diagnostic measurement tools are essential for the successful completion of combustion science experiments in the microgravity environment. The self containment required for drop tower and space based experiments imposes size, power consumption, safety, vibration and shock tolerance, and system complexity constraints that render most "common" laboratory techniques unusable. Consequently, initiatives are underway to develop new diagnostic tools for: (1) flow visualization and qualitative imaging, (2) determination of temperature and species concentration fields, (3) determination of velocity fields, and (4) measurement of particle size distributions and concentrations.

\section{DISCUSSION}

WSU Mechanical Engineering student, David A. Nordling was selected and sent to NASA Lewis for a 31 week internship in 1995. He worked alongside NASA scientists and engineers to assist in the performance of several ongoing research projects in the area of microgravity combustion science. Specifically, he was

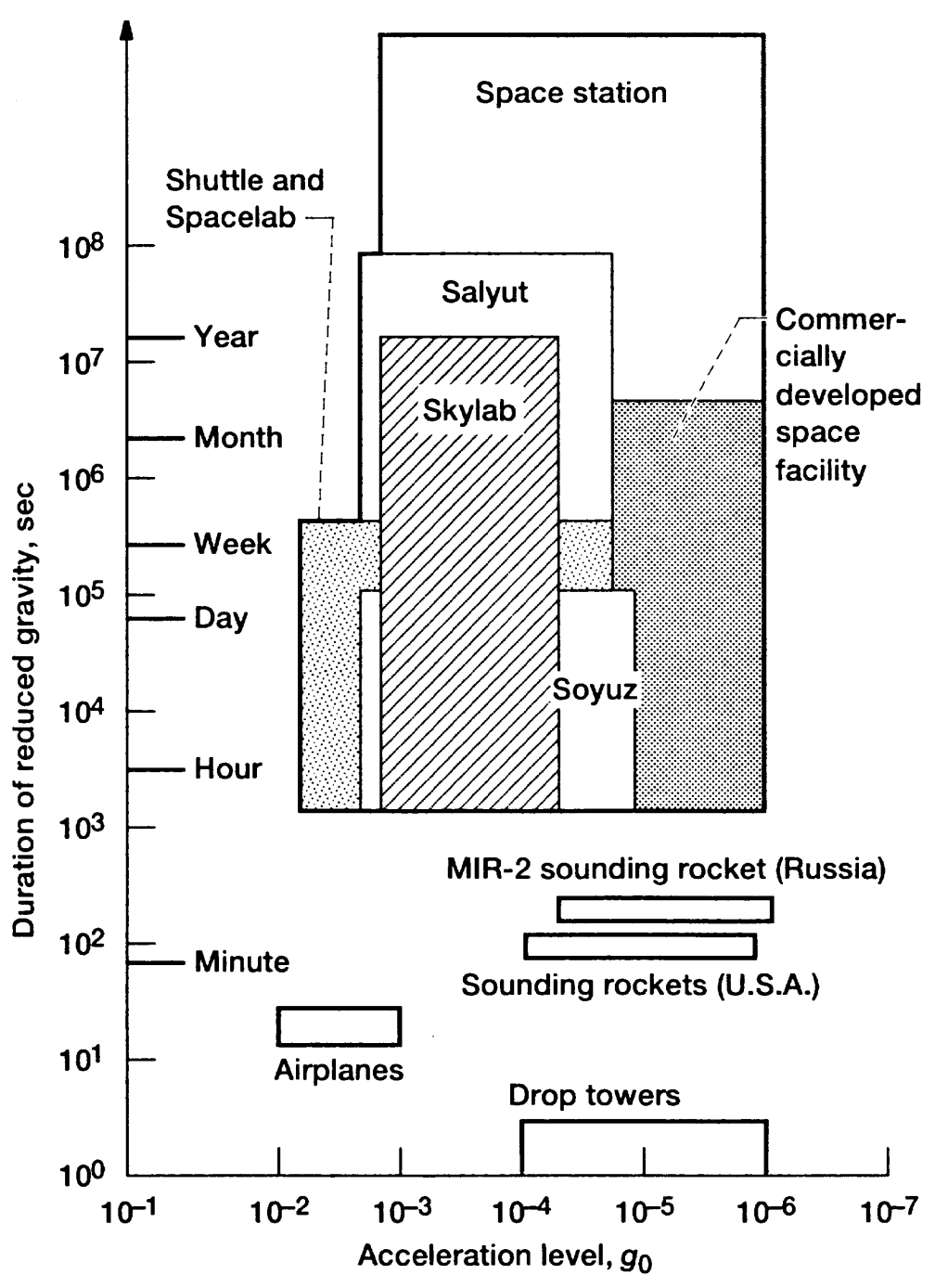

FIGURE 2. Characteristic times and acceleration levels of reduced gravity laboratory facilities. (NASA, 1992) 


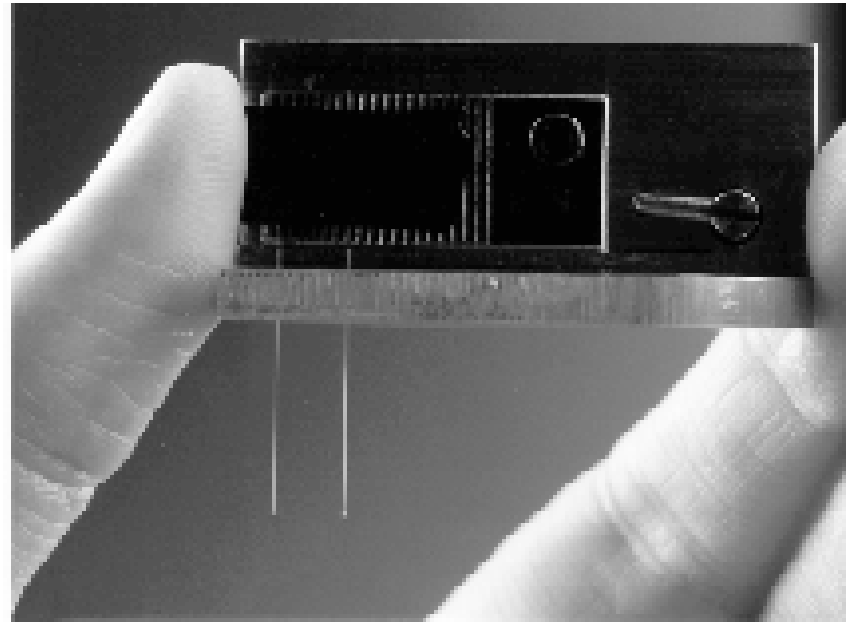

FIGURE 2. Droplet holder for droplet combustion test rig showing filaments. involved in studies of the behavior of candle flames, and the ignition/combustion characteristics of liquidfuel droplets and solid-fuels in the absence of gravity. The work was primarily experimental, using normal gravity, drop towers and reduced gravity aircraft. By involvement in the research effort, the student was given the rare opportunity to work with unique facilities in a national laboratory, e.g. drop towers, aircraft; and to use state-of-the-art instrumentation/equipment in unique combustion science laboratories. The research experience gained by the student during his participation in the project has supplement his academic program, and helped to motivate him to pursue a career in research and to attend graduate school.

Worthy of particular note was the student's work to re-engineer an automated droplet combustion rig for use in drop tower experiments. Figure 3 shows a

close-up view of the fiberglass droplet holder used in the test-rig. This self-contained unit is placed in a drop tower package, which, when dropped, begins a complex set of data acquisition and control operations. At the instant free fall begins, the control system ignites the droplets which are held at the end of the pictured filaments. The ignitor is then retracted. All the while data acquisition systems, including video imaging, are recording the combustion process. This entire set of operations occurrs during a 2 to 5 second run. Subsequent to the experiment, video image analysis is performed to determine burning rates, etc. Video footage of droplet burning experiments conducted by the student are shown during the multi-media presentation.

\section{CONCLUSIONS}

In view of the above, it is apparent that providing students with the opportunity to become familiar with these new and unique approaches to scientific experiments is important and necessary. Thus, the overall objective of the NASA Educational Grant program for microgravity combustion research, to prepare the next generation of professionals to work in space endeavors, has been met. Specifically, the program: (1) captures student interest in the science of microgravity combustion; (2) improves student performance in science; and (3) provides a unique opportunity for undergraduate students in engineering to conduct research, and enhance their performance in combustion science.

\section{REFERENCES}

Vannevar Bush (1945), "Science: The Endless Frontier," United States Government Printing Office, Washington, D.C.

Leon M. Lederman (1995), "Public Science Literacy Must Be Increased to Stem Tide of AntiScience Sentiment, The Scientist, 9:14, p.13.

NASA (1992), “Microgravity Combustion Science: Progress, Plans, and Opportunities," NASA Technical Memorandum 10510, NASA Lewis Research Center, Cleveland, OH. 